\title{
SOCIAL AND INDIVIDUAL SIGNIFICANCE OF AGEING
}

$\mathrm{T}$ HE presence of some five hundred delegates from more than fifty countries in London during July 19-23 for the third Congress of the International Association of Gerontology must be considered an important stage in the gestation of a 'science of ageing' in Great Britain. The three main sections were: (1) Biology and Pathology; (2) Geriatric Medicine and Psychiatry; and (3) Social and Psychological. This report will be restricted to the sixty or more papers in the third section. Dr. J. $H$. Sheldon in his presidential address stressed the dominance of the social implications of gerontology, and said that "in many countries old age is likely to become the major social problem over the next twenty years". He emphasized the necessity for keeping a sense of proportion, "remembering that those aspects of the therapeutic art which happen to possess greatest technical interest and challenge are not necessarily those of the greatest social importance".

There was considerable appreciation in this third section-though not confined to it-that the major concern should be with the quality rather than the quantity of the later years; that fundamental and applied research should now be directed more towards social and individual adjustments to an already greatly increased expectation of life, rather than to adding still further years to life. A prime objective, as Dr. Sheldon put it, is "so to maintain the general vigour of the old that their capacity to contribute to the common effort and above all to maintain their domestic independence, is retained as long as possible".

The sessions in this third section could be grouped into three main divisions, with the first providing the background. The second such division, here considered as "The Care and Welfare of the Aged and the Ageing", related more to the negative aspects of age, those of atrophy, degeneration and decline, and was concerned with ensuring better provision of medical and social care for those requiring this as a consequence of the infirmities of ageing. These sessions were: "Residential Care", "Integration of Plans for Care in Health and Infirmity" and "Personal Services, Community Activities, Casework and Counselling". The third grouping of sessions took greater cognizance of the positive aspects of ageing, those of growth, development and maturation: "Employment Problems of Older Workers", "Employment of the Elderly" (plenary session), "Experimental Study of Skill in the Elderly" (joint session with Section 1) and "Education for Later Maturity in the U.S.". A general heading here would be "The Utilization of Later Maturity".

\section{Social Policy and Practice}

The three main speakers in the first session, "Introduction to Problems of Social Policy", were Prof. A. Sauvy (Paris), dealing with the historical basis of gerontology, Sir Godfrey King, who provided a descriptive analysis of the operation of contemporary provisions for old age in Great Britain, and Prof. E. W. Burgess (Chicago). Prof. Sauvy outlined the three successive ways in which society has looked after its old people - a 'family phase', an 'individualist phase', and a developing 'social phase'. He considered that "the whole problem of old age must be placed on a new basis, or rather it is posed for the first time in an urgent fashion". Sir Godfrey stated. that "if in general terms, we define our policy as being an intention to make old age as tolerable and pleasant as we can, many things will have to be done which will call for social decisions of the widest possible character", and that "we have only recently started to give special attention to problems of old age in this country".

Prof. Burgess discussed "The Human Aspects of Social Policy". He laid stress on a need, in planning for the well-being of older persons, for the realization that they "have essentially the same basic values and wishes as all other human beings". A social policy commensurate with the problems of ageing must take this into account-and also "the deteriorating role of older people in modern society". Older people, Prof. Burgess affirmed, have the desire common to others to engage in meaningful activities and to participate in and identify themselves with society : their need for a feeling of security is psychological as well as economic. In "meaningful activities" he included both work and recreation: "the findings of research indicate that work is not solely or even primarily a way of earning a living. It is a way of life by which people regulate and routinize their time, associate with their fellow workers, make use of their skills, gain recognition, achieve status, nurture a feeling of usefulness and find expression in creative activity and in the service of others".

The "Symposium on National Programmes" was not very informative, and it would appear that, strictly speaking, such programmes on age and ageing are not yet in evidence.

Mr. Clark Tibbitts, the chairman of the plenary session, "Critique of Surveys", specified the three areas of inquiry as : general conditions and adjustment of the elderly, their health status, and various aspects of employment of older people. The three papers provided illustrations of these. Dr. M. L. Barron (Cornell) described a nation-wide longitudinal investigation initiated in 1952 to study the effects of occupational retirement and the relationship between health, economic, psychological and social factors in old age; Dr. J. V. Zonnefield reported a medicosocial survey of the aged in the Netherlands; and Mr. L. Moss commented on the data from the 1950 Ministry of Labour sample survey on the employment of the elderly. The chairman had pointed out that the primary concern for that session was in survey methods : "are the methods in use satisfactory for getting the kind of information wanted ?"

Mr. Moss stated that the main purpose of the Social Survey inquiry was to get "an all-round appraisal of the problem". He gave an account of the rationale of the cross-sectional representative sample survey, showing its relation to detailed inquiries concentrating on one special aspect of a problem. Dr. Barron pointed out that longitudinal studies of the ageing process are better equipped to show relationships between certain factors than are cross-sectional surveys. In his address opening the discussion, Mr. Mark Abrams expressed doubts 
whether the survey methods in use in Great Britain are fully satisfactory : "we are in danger of merely multiplying our stock of familiar facts". He advocated a considerable widening of the age-span normally considered in old-age surveys, the use here of longitudinal studies of ageing, and also the necessity for a multi-discipline approach : "Hitherto statisticians and medical men have tended to have a monopoly of the planning, direction and interpretation of surveys; research would be more illuminating if their tasks were shared with experts from other fields-sociology, economics, architecture, government and even history".

\section{Care and Welfare of the Aged and the Ageing}

There was general agreement among the speakers on the need to prevent any undue increase in the institutional care of the aged. Apart from the shortage of existing hospital and similar accommodation and the mounting social burden involved, Dr. G. Evans, among others, emphasized that it is in the interests of older people that "residential care should be exceptional rather than normal"; main emphasis should be put on preventive work and rehabilitation. But though infirmity was not accepted as a dominant or necessary characteristic of later years, it was recognized that a greater incidence of this must be expected in the final years of life, and also that the increased numbers and proportion of the aged have already made heavy demands on available medical and nursing facilities. Dr. R. C. Walsh spoke of an inadequate response to the problem of the elderly sick and infirm as an "overshadowing challenge" calling for "an imaginative response from health and welfare organizations".

In his paper, "Making the Best of Available Accommodation", Dr. G. W. H. Townsend advocated that hospital beds should "be occupied by the right people and for as short a time as possible" and that "if we are to decrease the demand for beds, every precaution must be taken to see that the aged persons remain self-sufficient or at any rate members of their own family as long as possible". He stressed the value of day hospitals such as that pioneered by Dr. Cosin in Oxford. Dr. Nain Cowen spoke later of the Rutherglen Health Centre for Old People, the chief purpose of which is to keep older people active and healthy at home.

From the chair, Mrs. M. M. C. Kemball had directed attention to a required partnership embracing the family, the voluntary bodies and the statutory services for ensuring the health, care and attention of older people. Various delegates spoke of the importance of enabling the family to make its vital contribution to this partnership and gave accounts of ancillary services and aids provided by voluntary and statutory bodies for this purpose, and to help preserve the independence of the elderly.

Many speakers discussed what is in effect another type of welfare as most appropriate to those not functionally old, that being to allow, encourage and enable them to live substantially normal lives for as long as possible with continued exercise of their capacities and for a fuller development of their personalities over the penultimate period of life. Mr. L. Kuplan's paper, "The Community and the Senior Citizen", was a declaration of the principles basic to this approach, as well as a report of what he described as "an exciting demonstration of democracy in action". He said that, following a State-wide con- ference on the problems of ageing held in 1951, "the State of California and many of its cities and towns have accepted the principle that the older person must be encouraged and helped to remain an integral and contributory member of the community. Accepted also the corollary principle that the older. person must be permitted to live through the later years in self-respect, dignity, security and usefulness". Dr. C. O. S. Blyth Brook, for one, spoke of the sense of service to others as well as the physical and mental exercise involved in suitable employment, as factors checking the conversion of senescence into senility. Dr. J. Weil (Ohio) said "the older person content only with leisure must lose his self-esteem-of purpose for living". The place and purpose of recreation for the well-being of the elderly was discussed by Miss G. E. Bowen (Philadelphia) and Miss V. Ingram (New York). They interpreted its true role as re-creation, so as "to bring the older persons back into the stream of life and help them maintain a maximum of mental health and usefulness" in "an active, creative routine instead of a dull, monotonous one".

\section{Utilization of Later Maturity}

"The goals of gerontology must not be viewed as revolving around putting oldsters to work, but to assure that older workers who need work, want work, and who can be fitted for work are given equal opportunities with others to obtain work." In saying this, Mr. A. J. Abrams (New York) had in mind "culture-borne negative attitudes to ageing" as an infringement of democratic, equalitarian concepts. He reported discrimination against older workers as universal, and even evident well before the sixties. $\mathrm{He}$ spoke also of initial steps being taken to offset this through job analysis, physical examinations, job counselling, re-training and "re-engineering of jobs to adapt them to ageing workers". An international pooling of data was advocated. But Mr. Abrams felt that, though more technical knowledge is required, there are "enough data already available-so that any country, determined to aid its older workers, need not flounder". Mr. J. A. Scott, in his "Placement of Older Workers", described successful Canadian experiments in older-age counselling. Dr. I. M. Richardson suggested that encouragement and enablement of older workers to go on working efficiently longer than at present is the central problem which would help to solve other problems of old age; but that true preventive measures must be made from the fifties or even earlier.

In his earlier commentary on the 1950 Social Survey, which showed that 23 per cent of the men had retired before sixty, average retiring age being sixty-two, Mr. Moss mentioned that the investigation had also shown no marked difference in the age at which men gave up jobs in different industries and occupations. An implication of this was, he felt, that it was not the actual demands of the job which determined time of retirement but rather attitudeson the part of the workers themselves and of management. Mr. A. J. Abrams considered that though "oldsters themselves tend to accept the community's image of the older worker", there is a changing of attitudes from retirement, even early retirement, as a life goal. One finding of the British survey was that, at sixty-five years of age and older, much larger numbers of people had stated that they went on working because they preferred to be occupied, irrespective of economic necessity. In a later paper, 
Mr. J. Roberts dealt with factors in the trade union attitude to this question. $\mathrm{He}$ indicated that the principle of "the right to work" is now tentatively being extended to "the right to work for all adults irrespective of age".

Several papers touched on attitudes of employers to the employability of older workers. Mr. Moss felt that in spite of "a limited amount of goodwill" on the retention and taking on of such workers, "the prospects do not appear to be very favourable as long as present attitudes are dominant". Mr. A. J. Abrams mentioned the ineffectiveness of 'exhortation' or even 'proof' for removing age barriers in industry, and the necessity "to motivate top-management to examine personally this problem". "A Report on the Effectiveness of 3,000 Older Workers in a Sampling of American Business Firms" was given by Mr. R. L. Peterson. In this inquiry older workers were evaluated by their immediate supervisors, who used as a comparison "their concept of the average younger worker". The report findings, on those more than sixty years of age, showed "a work volume about the same as for younger workers", as well as less absenteeism, greater reliability and work of better quality. He stated that studies of this kind are influencing American employers to modify their employment programmes.

Mr. A. T. Welford outlined "a minimum programme of research" of an experimental psychological nature on capacities and job demands, which he felt would need to be completed "before a confident policy for employment of older people could be framed". But he pointed out that there are other questions demanding "a method of study which so far has been little used for work on ageing". Examples of these given by Mr. Welford were, "the direct measurement of performance at work on the shop floor and ... experiments in modifying work to older people". In the joint session, "Experimental Study of Skill in the Elderly", Dr. H. E. Jones (California) observed that "the study of age changes in human abilities has a scientific history of hardly more than twenty years" ; Mr. W. T. Singleton pointed out, moreover, that "research in the field of gerontology would appear to have been more concerned with somatic changes than with psychological ones". There were a number of references to the decline of certain mental abilities from a quite early age; but Mme. S. Pacaud (Paris), referring to her experimental studies, emphasized the importance of education as a check on the destructive effects of ageing, and Dr. D. Wechsler (New York) discussed the problems of appraising intelligence in older people; he questioned "whether identical tests identically performed measure the same thing" in this connexion; he also suggested that sagacity or wisdom is an added aspect of intelligence at later years.

Although the papers in the session "Education for Later Maturity" were all contributed by American speakers, a number of other delegates in various sessions stressed the importance of this factor. Three aspects of such education were considered : for personnel concerned with the care of the aged, for the ageing person himself, and for the community in general. Mr. A. J. Carlson discussed the value of adult education in "preparation for the senior years". Mr. O. J. Kaplan, in "Communication of Health Knowledge to Older Persons by Radio and Television", observed that "advances in gerontology have little meaning unless they are reflected in the life and habits of older persons . . . though there was much knowledge already it was misunderstood and unknown by many over 60". Two papers on projects for laterage education were given by Dr. Ruth Andrus and Dr. Wilma Donahue, and Dr. W. H. Reals, speaking on "Programmes for the Ageing in American Universities", reported their rapid development during the past six or seven years. From his surveys, Dr. Reals concluded, "there appears convincing evidence that the problems of ageing and educational provision for the older adult himself have become a definite and increasing concern of universities in the United States".

What would amount to a fourth aspect of 'education' on ageing was indicated by Dr. E. Digby, who questioned "whether there is sufficient thinking together of the biological, psychological and social sides". Miss E. I. Black also, as chairman of this third section, felt that it had a lot to learn from the discussion in the other sections- "but that the traffic should not be one way". This consideration, however, presupposes some evenness in the contribution of research data from the different fields of gerontological inquiry. Though ageing has now become "a major socio-medical problem", it is perhaps significant that there were very few papers of an essentially sociological character in this third section originally specified as "Sociology and Psychology". Dr. Sheldon's comment on "a lack of fundamental thinking in our approach to old age" appears to have a bearing here. In his address, however, Sir Godfrey King had remarked that, with other communities in similar demographic circumstances, "we are now going through a process of adjusting ourselves to the facts". There was an agreement among speakers that research findings from different fields of investigation would need to be taken into account by other specialists if the required unified though multi-aspect science of gerontology is actually to be constituted for the welfare of society.

C. Fleming

\section{BEECH MYCORRHIZA}

$\mathrm{A}$ $T$ the British Association meeting in Oxford on September 3, three papers were read before Section K (Botany) under the chairmanship of Dr. J. L. Harley on the subject of ectotrophic beech mycorrhizas. A great deal of progress has been made in recent years on this subject at Oxford by Dr. Harley and his collaborators: the speakers were pupils of his.

The first speaker, Dr. J. K. Brierley, showed that beech mycorrhizas consisted of a fungal sheath 25-40 $\mu$ thick which surrounded a core of host tissue. An account of experiments was given which helped to determine a route by which phosphorus passed through the fungal sheath to the host. He showed that when roots which had been exposed to labelled phosphate were transferred to phosphate-free aerated buffer solution, part of the phosphorus accumulated by the fungus during exposure to phosphate is redistributed to the host during the subsequent stage in phosphate-free buffer. Although previous experiments have shown that movement of phosphorus to the host takes place during absorption from an external supply, the experiments described here showed that movement could take place from previously accumulated phosphorus in the fungal tissues to the host in the absence of an external phosphorus supply. Redistribution, as this movement was 